Joachim Kokkelmans (Verona)

\title{
Middle High German and modern Flemish $s$-retraction in /rs/-clusters
}

Abstract: Late medieval High German experienced a systematic sound shift, although not consistently reflected in modern standard German, which transformed $/ \mathrm{rs} /$ into $/ \mathrm{r} \mathrm{f} /$. It is argued that this sound shift must be analysed phonetically as a perseverative tongue shape and place of articulation assimilation from [rs] to an apical retracted alveolar [rs], followed by the phonological reanalysis of a perceptually ambiguous $[\mathrm{rs}]$ as $/ \mathrm{r} \int /$. This analysis implies the hypothesis that only alveolar rhotics can trigger s-retraction in /rs/, not uvular rhotics. Approximatively seven hundred years after the MHG s-retraction, a similar sound shift occurs in Flemish varieties of standard Dutch. A pilot study with Flemish speakers confirms that the motivation for $s$-retraction in $/ \mathrm{rs} /$ must be attributed to an alveolar $/ \mathrm{r} /$. Further typological inquiries into the historical phoneme inventories of English, Dutch and German varieties, reinforced by the comparison with other (non-)Germanic languages, also confirm this hypothesis.

Zusammenfassung: Im Mittelhochdeutschen trat eine Lautverschiebung auf, bei der $/ \mathrm{rs} / \mathrm{zu} / \mathrm{r} \mathrm{J} /$ wurde, obwohl sie nicht konsequent im modernen Hochdeutschen widerspiegelt ist. Es wird postuliert, dass diese Lautverschiebung phonetisch als eine progressive Zungenform- und Artikulationsortassimilation von [rs] zu einem apikalen retrahierten alveolaren [rs] zu verstehen ist, wonach ein perzeptuell zweideutiges [rs] als /rf/ reanalysiert wurde. Diese Analyse bringt die Hypothese mit sich, dass nur ein alveolares $/ \mathrm{r} / \mathrm{s}$-Retraktion in /rs/ verursachen kann, nicht aber ein uvulares /R/. Etwa siebenhundert Jahre nach der mhd. s-Retraktion tritt offensichtlich die gleiche Lautverschiebung in flämischen Umgangssprachen auf. Eine Pilotstudie mit Flämischsprachigen bestätigt, dass die Motivierung für $s$-Retraktion in /rs/ einem alveolarem / $\mathrm{r} /$ zuzuschreiben ist. Weitere typologische Beobachtungen über die historischen Lautinventare des Englischen, Niederländischen und Deutschen, vom Vergleich mit anderen (nicht-)germanischen Sprachen ergänzt, bekräftigen diese Hypothese.

\section{Introduction}

The study of sound shift, to be most accurate and reliable, should be equally based upon three pillars: phonological theory, phonetic observations and typological

D Open Access. (C) 2020 Kokkelmans, published by De Gruyter. (c) Br.NC.ND This work is licensed under the Creative Commons Attribution-NonCommercial-NoDerivatives 4.0 License.

https://doi.org/10.1515/9783110668476-008 
evidence. The risk of doing phonetics without phonology is that of missing the system-related reasons behind a specific observation, whilst the risk of doing phonology without phonetics is that of losing consideration of the practical articulatory reasons which motivate and condition a certain pattern. Finally, typology allows to verify phonetic observations and phonological generalisations inside the larger frame of natural languages. ${ }^{1}$

Furthermore, a well-balanced study needs not only to rely on diachronic, but also on synchronic comparison, since "no linguistic state of affairs can have been the case only in the past” (Lass 1997: 28). Synchronic evidence (in this case, from regional Flemish standard Dutch) sheds light on similar diachronic developments which are too old to have been studied in real time (in this case, Middle High German s-retraction in /rs/).

This paper will thus not only analyse the sound shift from /rs/ to /rf/ in West Germanic languages from a synchronic and diachronic perspective, but also illustrate more generally how phonology, phonetics and typology can (and should) work altogether to understand a specific development in natural languages. I first show that $s$-retraction in /rs/-clusters, at a phonetic articulatory level, is only triggered by alveolar rhotics, due to the shape and placement of the tongue; then, that at a phonological perceptual level, it consists of the reassignment of the resulting phonetic output $[\mathrm{s}]^{2}$ to a more posterior phoneme category, due to acoustic closeness to that category; and I conclude with typological data which supports this.

In the next section (2.1), I describe two similar and independent processes of $s$-retraction in the consonant cluster /rs/: one which spread through late medieval Germany, and one which is active in modern Flemish standard Dutch. I then present in 2.2 the existing literature dealing with this sound shift and formulate in section 2.3 a hypothesis which accounts better for the empirical observations made in 2.1.

Section 3 contains a theoretical phonetic analysis of this sound shift as a perseverative tongue shape and place of articulation assimilation. On the phonological side, I show how the phonetic output is reattributed to a more posterior sibilant phoneme category.

1 I wish to express my deep gratitude to Anne Breitbarth for her supervision, advice and support, and to Torsten Leuschner for his review and encouragement to publish this paper. Thanks also to two reviewers for their precious comments and to Heleen Van Mol for telling me literally that "certain pershons in Flandersh do it, but I don't".

2 The IPA notation [s] (with a minus sign indicating retractedness) stands for a voiceless retracted alveolar sibilant. The additional subscript $\mathrm{g}$ indicates apicality. 
In section 4, I focus on the diachronic and synchronic rhotic and sibilant inventories of English, German, Frisian and Dutch to demonstrate the hypothesis of this paper by means of cross-linguistic comparison, supported by an acoustic study of Flemish Dutch.

In section 5, I present additional typological data from other languages which have or have had a similar sound shift, including e.g. Afrikaans and Basque. I then conclude with some remarks on the conservative sibilant inventories of Dutch, Frisian and Low German, compared to English and High German innovations.

\section{Problem description and hypothesis}

\subsection{Two West Germanic processes of $s$-retraction in /rs/}

Starting around the fourteenth century (Hall 2008: 231f.), High German dialects experienced a systematic sound shift from $/ \mathrm{rs} /$ to $/ \mathrm{r} /$, which reached approximatively the border with Low German dialects without spreading further northwards. This change is reflected, although not systematically, in modern standard German. Examples of this are (adapted from Hall 2008: 231, quoting Russ 1982: 77, 1978: 81):
a. MHG ki[rs]e > NHG Ki[rf]e
Kirsche "cherry"
b. MHG hi[rs] > NHGHi[rf]
Hirsch "stag"
c. MHG ve[rs] > NHG $\mathrm{Ve}[r s]$
Vers "verse"

As a) and b) illustrate, this sound shift affected /s/ both from an original Old High German */s/ (compare Dutch kers) and from the deaffrication of the result of the OHG consonant shift */t/ > / $\mathrm{t}$ )s/ (compare Dutch hert). Example c) shows that not all standard German words were affected, something which is motivated by the historical process of heterogenous variant selection in written standard German. ${ }^{3}$

Contrary to most modern German varieties, some German dialects still had $s$-retraction in $/ \mathrm{rs} /$ as a productive rule in recent times, for example the Swiss dialect from Jaun (adapted from Hall 2008: 232, quoting Stucki 1917):

3 Standard German, originally only a written language, is predominantly based on High German but also has Low German loanwords, compare e.g. the doublets Wappen "coat of arms" - Waffen "weapons". Verse in 1c) can thus have been loaned from or influenced by varieties without $s$-retraction (compare French vers, Italian verso). 

a. Ferse
[fœ:rfəna]
"heel"
b. ein sauber-es [əssu:fər]]
"a clean (one)"
c. gib mir (e)s
[gimər]]
"give it to me"

As b) and c) show, the rule is not only productive inside single morphemes, but also across morpheme and word boundaries respectively. When functioning productively, $s$-retraction in /rs/ seems to operate independently from morpheme and word boundaries, as long as $/ \mathrm{r} /$ is immediately followed by $/ \mathrm{s} /$. This is not the case in modern standard German, where it doesn't work across morpheme or word boundaries (compare e.g. warst [va:(ь)st] “you were”, not [va:(в)ft]; wieder so [vi.də(в).zo] "again so", not [vi.də(в).30] in the IDS database of spoken German, DGD: FOLK_E_00288). It can be concluded that the standard German words with /rf/ from /rs/ in fact contain "fossilised" traces of a once-active rule, something which is confirmed by its absence in newer loanwords (e.g. Star Wars [sta:в.wว(в) s], DGD: FOLK_E_00288).

This raises the following question: why did the MHG s-retraction in /rs/ continue to work in certain dialects, but stopped functioning in others and in modern standard German? Another question, raised by Hall (2008: 214) and more generally known as the actuation problem (Weinreich/Labov/Herzog 1968: 102), is: Why did only Middle High German experience this change, and not Middle Low German or Old High German? In this paper, I give answers to both questions, showing 1) that the phonetic properties of both $/ \mathrm{r} /$ and $/ \mathrm{s} /$ allow or impede $s$-retraction in /rs/, something which explains why it was maintained as a productive rule only in certain German dialects, and 2) that this sound shift was hindered in Low German, Frisian and Dutch because of their conservative sibilant inventories as compared to High German and English.

Seven hundred years after the hypothesised start of MHG $s$-retraction in /rs/, evidence from an own study on Flemish Dutch (Kokkelmans 2017) shows that the same rule is active in certain Flemish varieties, in which /s/ after /r/ has significantly different phonetic characteristics from [s], being much more []]-like. More precisely, phonetic measurements yield acoustic values halfway between those of [s] and [f] (Kokkelmans 2017: 35f.), closest to those of a retracted alveolar [s]].

In the regional Flemish standard Dutch varieties which have $s$-retraction in $/ \mathrm{rs} /$, it is observed to occur inside words as well as across morpheme or word boundaries, as demonstrated by the informant named Alveolar4 in the study (Kokkelmans 2017):
a. Uw pe[rs]oonlijke mening "your personal opinion" 

b. Ande $[r z] i j d s(=$ ander $+z i j d-+-s)$
"on the other hand"
c. Dat er daa $[r][z]$ ogezegd
“(...) that there, so to say (...)"

Example b) and c) show that in voiced contexts (with underlying /z/), the result of the sound shift is $[z]$. In these Flemish varieties, the $/ r /$ is still phonetically realised, meaning that $[\mathrm{s}]$ and $[\mathrm{z}]$ are contextual allophones of $/ \mathrm{s} /$ and $/ \mathrm{z} /$ after $/ \mathrm{r}$, but in other varieties (e.g. East Limburgish, see 3.2), the $/ \mathrm{r} /$ has been vocalised or dropped. Despite r-loss, listeners can often reconstruct the pattern as $/ \mathrm{r} / \mathrm{t} / \mathrm{s}, \mathrm{z} /$ thanks to grammatical and lexical paradigms (e.g. Noors [no:s] "Norwegian” vs. Noorwegen [no:r.we.xə] "Norway”).

The fact that the informant uses alveolar $[\mathrm{r}]$ as the phonetic realisation of $/ \mathrm{r} /$ is of crucial importance for this study, since I claim that only an alveolar / $\mathrm{r} /$ allows $s$-retraction in /rs/ to start working as a productive rule. In fact, it has been claimed in the literature that the motivations of this sound shift are independent from the phonetic properties of $/ \mathrm{r} /$ and $/ \mathrm{s} /$, something which shall be refuted in this paper.

\subsection{Existing literature about $s$-retraction in / rs/}

Hall (2008: 215) describes the MHG shift from /rs/ to /rf/ as "a sound change that has perplexed generations of Germanicists". According to him, "there has been a tradition in the literature of either simply describing [s-retraction in $/ \mathrm{rs} /, \mathrm{JK}$ ] without explaining [it] or of proposing a superficial explanation that does not stand up under closer scrutiny". He rightly recognises the lack of a comprehensive study to understand the motivations of this sound shift, since most mentions of $s$-retraction in /rs/ in various languages (e.g. Eliasson 2000; Ewald 2015; Pedersen 1895; Schmitt 2015; Torp 2001) are exclusively descriptive and do not formulate any hypothesis to explain it. Furthermore, I found no mention of the Flemish $s$-retraction in /rs/ in the literature, despite its contemporality making it especially relevant to understand this sound shift.

To explain why this change happened in MHG and not in OHG or Low German, Hall (2008) proposes a phonological analysis based on the distinctiveness of the feature [high] (which distinguishes $/ \mathrm{J} /$ from $/ \mathrm{s} /$ ) as the key in understanding what he considers as a height dissimilation. I will argue instead for a place and tongue shape assimilation from [(dento-)alveolar] and [laminal/apical] (features of [s]) 
to [retracted alveolar] and [apical] (features of $[\mathrm{r} / \mathrm{r}]^{4}$ and $[\mathrm{s}]$ ). This analysis as an assimilation of the alveolar place of articulation implies the hypothesis that $s$-retraction in /rs/ only arises in languages in which $/ \mathrm{r} /$ is realised as an alveolar /r/. This contradicts Hall's (2008: 233) statement that the exact (place of) articulation of these sounds doesn't provide the explanation for the sound shift, and his assumption that it can also be triggered by a uvular /R/:

One might hypothesize that the precise articulation of $/ \mathrm{r} /$ provides a clue, but I contend that the surface phonetic facts are not important for an understanding of the $[\mathrm{rs}]>\left[\mathrm{r} \int\right]$ change. Consider the fact that there are dialects like the one spoken in Jaun in which the change takes place after an apical $/ \mathrm{r} /$, but that there are also dialects in which the change occurs after a uvular /R/ [...] It needs to be stressed that it is the phonology of $/ \mathrm{r} /$ and /s/ [...] and not the phonetics of these segments which explains rs-Dissimilation. Fine-grained surface phonetic facts are not important for the analysis I propose [...].

Against the view that $s$-retraction in /rs/ is not motivated by phonetic properties, I will argue and show that "it is mainly the concrete, phonetic properties of speech sounds that trigger or allow changes to take place in the sound system, and determine their subsequent development" (Chen/Wang 1975: 278). Taking phonetics, phonology and typology into account, this paper proposes another explanation for $s$-retraction in /rs/, and by pointing at the similarities between MHG and contemporary Flemish, it will account better for its motivations and its (non-)occurrence in Germanic languages.

A similar sound shift, described amongst others by Stausland Johnsen (2012: 509ff.), is the Scandinavian retroflex assimilation which transforms [s] into a postalveolar retroflex [s] after an alveolar [r] or a retroflex postalveolar flap $[\mathrm{r}]$. He demonstrates that there has been an intermediate step where an apical alveolar $[\mathrm{r}]$ transformed a laminal alveolar [s] into an apical alveolar [s], which corroborates the hypothesis of a tongue shape assimilation, whilst he doesn't make any distinction in place of articulation between [alveolar] and [retracted alveolar]. Retroflex assimilation can likewise be understood as triggered by a place of articulation and tongue shape assimilation, but it distinguishes itself from "non-retroflex" $s$-retraction in $/ \mathrm{rs} /$ to the extent that it applies to all alveolar consonants, including / $\mathrm{t}, \mathrm{d}, \mathrm{n}, \mathrm{l} /$, to yield /t, $\mathrm{d}, \mathrm{n}, \mathrm{V}$.

Stausland Johnsen (2012: 513-519) shows that although the vast majority of Norwegian and Swedish dialects either have alveolar $/ \mathrm{r} /$ and retroflexion or uvular /R/ and no retroflexion (i.e., retroflex assimilation and uvular / R/ seem to be

4 I consider the prototypical place of articulation of $[r / r]$ in languages with only one alveolar rhotic phoneme to be [retracted alveolar] for reasons detailed in section 3.1 . 
mutually exclusive), two exceptions exist at the border between /r/ and /R/: the Frogner dialect had retroflexion and later innovated by replacing / $/$ with / R/, whilst the Arendal dialect had /R/ and no retroflexion, and "adopted the retroflexion process from neighbouring dialects" (Stausland Johnsen 2012: 508). In both dialects, the sound shift is productive, also across morpheme and word boundaries. Stausland Johnsen (ibid.: 506) considers retroflexion in these varieties with / R/ to be an 'unnatural' process which "lacks any synchronic phonetic motivation". He shows that although these varieties seem to speak against the hypothesis of this paper, they are the historical consequence of intense language contact between varieties with / $\mathrm{R} /$ and varieties which still today have productive retroflexion. That s-retraction in /rs/ can be learned as a productive rule even when its phonetic motivation is absent does not contradict the hypothesis that the phonetic motivation for $s$-retraction lies in the assimilatory effect of an alveolar $/ \mathrm{r} /$ on a following /s/; it rather shows that language contact and historical developments can make s-retraction in /rs/ synchronically unmotivated, yet still learnable.

\subsection{Hypothesis}

From a theoretical perspective, $s$-retraction in $/ \mathrm{rs} /$ is posited to be a phonetic assimilation of place of articulation and tongue position which generates the output [rs], and a subsequent phonological reanalysis of this phonetic output as a more posterior phoneme category. The hypothesis of this paper can be summarised as follows:

- From a phonetic perspective, $s$-retraction in / $\mathrm{rs} /$ is a perseverative assimilation of the [apical] tongue shape and [retracted alveolar] place of articulation of $[\mathrm{r} / \mathrm{f}]^{5}$ to a following [(dento-)alveolar] and [laminal/apical] ${ }^{6}[\mathrm{~s}]$, which yields an [apical] [retracted alveolar] [s].

- From a phonological perspective, $s$-retraction in /rs/ is the allocation of this [s] in the phonetic output [rs] to a more posterior phoneme category than its original category. To be phonological, $s$-retraction necessarily implies a change

5 Since the difference between the alveolar trill [r] and the alveolar tap/flap [r] plays no distinctive role in this paper, $[\mathrm{r}]$ will hereafter refer to both $[\mathrm{r}]$ and $[\mathrm{r}]$ for economical purposes. The approximants $[x / \underline{x}]$, hereafter likewise written $[x]$, could theoretically also trigger $s$-retraction in $/ \mathrm{rs} /$, but this question could not be addressed here due to a lack of data. The retroflex approximant [r] can trigger retroflex assimilation (see section 4.1).

6 The initial tongue shape of [s] is not relevant here, since it becomes [apical] by means of the assimilation in any case. Dart (1991: 21, 26) shows that the pronunciation of (dento-)alveolar [s] in English and French freely variates between laminal and apical. 
of phoneme category, e.g. from /rs/ to /rs /, /rf/ or /s/. In two-sibilant inventories with $/ \mathrm{s} /$ and $/ \mathrm{S} /$, it consists more precisely of the reanalysis of a perceptually ambiguous phonetic output [rs] as an underlying / $\mathrm{r} /$ instead of /rs/.

- From a typological perspective, s-retraction in /rs/ is a sound shift which occurs, phonetically, in languages with a retracted alveolar $[\mathrm{r}]$ and a (dento-) alveolar [s] in /rs/-clusters, and phonologically, in languages which have a phoneme /s/ [s] and at least another more posterior sibilant phoneme category.

\section{Phonetic and phonological motivations for $s$-retraction in /rs/}

\subsection{Phonetic articulatory theory}

In this section, I explain why I consider the prototypical place of articulation of alveolar /r/ and /s/ in languages with only one alveolar /r/ or /s/ respectively to be [retracted alveolar] (as evoked in footnote 4), by referring to literature about articulatory economy and auditory dispersion. I then detail the articulatory motivations for $s$-retraction in /rs/.

The consonants [r] and [s] are standardly described in the literature as alveolar sounds, along with e.g. /t, d, n, l/, seldom with very detailed descriptions of their precise articulation place (as e.g. dento-alveolar, alveolar, retracted alveolar or alveo-palatal). For example, $[\mathrm{r}]$ is described as a sound produced when "the tongue blade and tip move up to the dental-alveolar-prepalatal region” (Barry 1997: 36, my emphasis). The wide range of described places of articulation is due to the wide range of different productions of these sounds: according to Ladefoged/ Maddieson (1996: 221), realisations of [r] "vary across speakers and languages in the location of the contact on the upper surface”. Boyce (2015: 261) shows for the English /r/ that "although many textbooks refer to /r/ as having an alveolar place of articulation, it is more accurate to say that it has a relatively undefined 'palatal' or 'post-alveolar' primary place of articulation”. This variation is explained by the phenomenon of permissible variation: "a category is allowed more auditory variation if it is alone on its auditory continuum than if it has neighbours from which it has to stay distinct" (Boersma/Hamann 2008: 222). This holds of course not only for perception, but also for production. For example, a speaker of a language with one single sibilant will be free to realise it as e.g. alveolar, retracted alveolar or palato-alveolar, but a speaker of a language with two sibilants will need to keep them apart (e.g. alveolar vs. palato-alveolar) in order to avoid con- 
fusion. This is described as auditory dispersion in Boersma/Hamann (2008). However, at the same time, articulatory economy tends to favour realisations which require less tongue movements from its average or rest position (Boersma/ Hamann 2008: 220f., 230; Shariatmadari 2006), such as retracted alveolar sibilants. Adams (1975: 290), Vijūnas (2010: 42) and Martinet (1955: 236f.) confirm typologically that languages with only one sibilant tend to have it realised as a retracted alveolar, with average (acoustic) centre of gravity-values ${ }^{7}$ on a scale from front (dental [s] $]$, highest COG) to back (postalveolar retroflex subapical [s] , lowest COG). Articulatory economy thus favours retracted alveolar rhotics and sibilants from an absolute point of view (i.e. considering the sound itself, independently from its phonetic or phonological environment). Languages with two sibilants, on the contrary, tend to have a dispersed contrast with [s] and [ $]$ ], pronounced far enough from each other - as (dento-)alveolar and palatoalveolar, respectively, with less permissible variation and strictly distinct centres of gravity. This also holds for coronal rhotics: Russian, for example, has a contrast between a palatalised dental trill $\left[\mathrm{r}_{\mathrm{j}}^{\mathrm{j}}\right]$ and a postalveolar trill [r] (Ladefoged/ Maddieson 1996: 221). This thus means that the place of articulation of coronal rhotics and sibilants will tend towards [retracted alveolar] when they are the sole phoneme of their class, and towards the extremities of their articulatory-auditory spectrum ([(dento-)alveolar] and [postalveolar]) when they contrast in place of articulation with another coronal rhotic or sibilant respectively. ${ }^{8}$

Concerning the apical-laminal distinction, Ladefoged/Maddieson (ibid.: 218) explain that trill and tap/flap [r]'s are predominantly apical:

Trills are much more easily produced if the vibrating articulator has relatively small mass, hence the most common trills involve the tongue tip vibrating against a contact point in the dental/alveolar region [...]. In fact by far the most common type of trill is one involving the tongue tip.

7 The centre of gravity (COG) of a sound is obtained by "weighing the frequencies in the spectrum by their power densities" (Boersma/Hamann 2008: 229).

8 When it comes to the statistical distribution of rhotics and sibilants in the languages of the world, a notable difference is found: amongst the languages which have at least one rhotic, it is most common (75.3\%) for a language to have exactly one rhotic, whilst only $18.9 \%$ of all languages have more than one (Wiese 2011: 713, based on UPSID). In particular, own calculations in the UPSID yield that, of languages with coronal trills or tap/flaps, $89.8 \%$ have just one. In contrast, only $52.6 \%$ of the languages with sibilants have exactly one, with $41.7 \%$ of all languages having more than one (UPSID). One is thus overall very likely to find languages with a retracted alveolar rhotic, and relatively likely to find languages with a retracted alveolar rhotic and a (dento-)alveolar sibilant. 
The only exception to this tendency known to Ladefoged/Maddieson (1996: 228) is the Czech fricative laminal alveolar $<\check{r}>/ \mathrm{r} /$, which however contrasts with a trilled apical alveolar /r/. In a language with one [r], it is thus predicted to be [apical] and [retracted alveolar]; in a language with two coronal rhotics, there will be at least one [apical] of both, either [retracted alveolar] as in Czech or [postalveolar] as in Russian.

Regarding sibilants, concrete phonetic observations made by Dart (1991: 22, $29,32)$ show that there is a correlation between the configuration of the tongue and the backness of /t, d, s, z, n, l/ in French and English: "the more apical the articulation, the farther back on the palate it is articulated" (Dart ibid.: 22). A striking exception to this tendency is however found in English apical /s/ and /z/, which are consequently articulated further forward. Dart (ibid.: 29) explains it as follows:

The explanation for this difference may lie in the fact, as stated by Catford (1977: 157), that the acoustic and aerodynamic differences between apical and laminal /s/ are more evident if they are alveolar than if they are dental. A retracted apical fricative opens up a large sublingual resonance cavity, which is characteristic of []] production and would presumably cause the $/ \mathrm{s} /$ to trespass on the acoustic space of this contrasting segment, an effect naturally to be avoided.

Dart (1991) and Catford (1977) thus make the crucial observation that /s/, which is (dento-)alveolar in well-dispersed inventories with two sibilants such as English, is prone to auditory misinterpretation as $/ \mathrm{J} /$ when it is apical and (retracted) alveolar. This explains phonetically the tendency of [s] to be reanalysed as $/ \mathrm{J} /$ (see next section). Stausland Johnsen (2012: 512), citing Anderson (1997), confirms independently that "there is an observed tendency for listeners [...] to asymmetrically misperceive apical alveolars as apical postalveolars”. Fronting the English apical /s/ to a dental place of articulation can be considered a strategy to prevent such a misperception.

As said above, articulatory economy favours retracted alveolar rhotics and sibilants from an absolute point of view. From a relative point of view (i.e. in a given environment, here "after a retracted alveolar [r]"), articulatory economy also favours [s] in [rs] to become [s], since it requires fewer movements of the tongue: instead of needing to move from [retracted alveolar] to [(dento-)alveolar] and (optionally) from [apical] to [laminal], the tongue keeps the same position and shape throughout the entire articulation of the cluster (i.e. [retracted alveolar], [apical]). Pragmatic evidence for this articulatory ease is the observation that both sounds can be pronounced simultaneously (sounding somewhat like the Czech fricative trill $<\check{r}>[r]$ cannot. 


\subsection{Phonological perceptual theory}

How [s], the output of phonetic s-retraction in /rs/, will be interpreted by the phonological system of a language depends on the sibilant inventory itself: how many sibilant phonemes (contrasting in place of articulation) it has, and to which mean phonetic realisation they correspond. A first prerequisite for phonological s-retraction in $/ \mathrm{rs} /$ is that there must be at least two phonetically distinct realisations, namely a (dento-)alveolar [s] and a retracted alveolar [s] after $/ \mathrm{r} /$. In one-sibilant inventories with a retracted alveolar [s] as prototypical realisation of /s/, s-retraction cannot occur because / $/$ / after / $/ \mathrm{r}$ is acoustically undistinguishable from another $/ \mathrm{s} /$, and no phonemic split or reanalysis as another phoneme can thus take place. A second prerequisite for phonological s-retraction in $/ \mathrm{rs} /$ is that $/ \mathrm{s} /$ after $/ \mathrm{r} /$ must be reassigned to a more posterior phoneme category, either by provoking a phonemic split or undergoing a reanalysis. In the first case, [s] becomes a phoneme of its own and contrasts with /s/, something which implies the loss of the conditioning context (i.e. $r$-loss). ${ }^{9}$ If however [s] fails to establish itself as a new phoneme, it will be reallocated to the phoneme category whose mean phonetic realisation is perceptually closest to [s]. In a three-sibilant inventory, this will be the middle phoneme category (e.g. /s/ [s] for Basque). In a two-sibilant inventory with a well-dispersed /s/-/J/-contrast, the phonetic output [s] is prone to reanalysis as /S/, as explained above by Dart (1991: 29) and confirmed typologically by Adams (1975) and Kwakkel (2008: 4). This is precisely what happened in Middle High German. The phonological motivation for $s$-retraction in $/ \mathrm{rs} /$ is thus the fact that $[\mathrm{s}]$ is perceptually biased towards being perceived as a more posterior phoneme category than its original category, and is therefore reallocated to that category.

\section{Typological comparison of West Germanic sibilant and rhotic inventories}

This section compares the phonetic realisations of the phonemes $/ \mathrm{r} /$, /s/ and $/ \mathrm{J} /$ in West Germanic varieties, from a diachronic and synchronic perspective. Whilst these languages all have $/ \mathrm{r}$ / as a phoneme, they mainly differ in having either a

9 No clear-cut example of this is known to me for the s-retraction described here, but it occurred as a result of the Swedish retroflex assimilation (see section 5), where /s/ did not merge with what is now /6/ and / $/$ /; and it could be the case for Afrikaans (Ewald 2015: 38), where /r/ before [s] "is almost inaudible" and [s] thus almost phonemic. 
sole /s/ (in Dutch, Frisian and Low German) or in having a contrast between (dento-)alveolar /s/ and postalveolar / $/$ / (in English and German). The West Germanic varieties described here have in total three different sibilants and three main realisations of $/ \mathrm{r} /$, as depicted in table I (NB: regardless of voicing).

Table 1: Attested combinations of rhotic consonants and sibilants in phonetic inventories of West Germanic languages

\begin{tabular}{|c|c|c|}
\hline & Retracted alveolar $[\underline{s}]$ & (Dento-)Alveolar [s] \\
\hline \multirow[t]{2}{*}{$\begin{array}{l}\text { Alveolar trill [r] or tap/ } \\
\text { flap [r] }\end{array}$} & $\begin{array}{l}\text { Some Netherlandic } \\
\text { Dutch varieties }\end{array}$ & Some Flemish varieties \\
\hline & & $\begin{array}{l}\text { Scottish English, Middle High German, } \\
\text { some southern German varieties }\end{array}$ \\
\hline \multirow[t]{2}{*}{ Uvular trill [R] or fricative [b] } & $\begin{array}{l}\text { Some Netherlandic } \\
\text { Dutch varieties }\end{array}$ & Some Flemish varieties \\
\hline & & Dutch Limburgish, modern standard German \\
\hline $\begin{array}{l}\text { Alveolar or retroflex } \\
\text { approximant }[\imath] \text { or }[\iota]\end{array}$ & $\begin{array}{l}\text { Some Netherlandic } \\
\text { Dutch varieties }\end{array}$ & Standard English \\
\hline
\end{tabular}

In the original Proto-Germanic sibilant inventory, there was most probably one $/ \mathrm{s} /$, for all modern occurrences of $/ \mathrm{J} /$ not found in loanwords result from consonant mutations and correspond to original Germanic clusters (e.g. /sk/, /sj/). Considering the observation made in 2.1 that one-sibilant inventories tend to have a retracted sibilant, this sole /s/ must have been realised as [s] , exactly as the modern pronunciation in the more conservative Germanic daughter languages (e.g. Icelandic, see Vijūnas 2010: 45).

The original phonetic realisation of $/ \mathrm{r} /$ is rather controversial in the literature, but considering the occurrence of $[\mathrm{r}]$ in Germanic languages which have been less exposed to direct or indirect French-speaking influence, it most probably corresponds to the original PG $\star / r$ / (see Trautmann (1880) and Chambers/Trudgill (1998), who consider the uvular /R/ a French innovation).

The following sections describe, for three groups of West Germanic varieties (English, High German and Dutch/Frisian/Middle Low German), first the development of $/ \mathrm{s} /$ and $/ \mathrm{s} /$, then the development of $/ \mathrm{r} /$, and subsequently why $s$-retraction in /rs/ did or did not happen in that group of languages. This shall allow us to test the hypothesis enounced above in detail on the West Germanic group, before extending the typological scope to North Germanic and nonGermanic languages in section 5. 


\subsection{Middle English and modern English}

English is most likely the earliest Germanic language to have developed the sibilant contrast /s/ - / /, by means of a palatal assimilation in /sk/-clusters which created $/ \mathrm{J} /$. Although the time of appearance of $/ \mathrm{J} /$ is (not undisputedly) estimated to be around the late Old English period (Cercignani 1983: 323), it must certainly have existed as a phoneme in the eleventh century, when a retracted [s] in Norman or Middle French loanwords was reanalysed as /J/ (Adams 1975: 283f.). Examples of such loanwords are push (Fr. pousser), leash (Fr. laisse) and punishment (Middle French punissement).

In most English varieties, $/ \mathrm{r} /$ mutated to the alveolar approximant $[x]{ }^{10}$ In some varieties, amongst which American and Irish English, it is pronounced as a retroflex approximant [^]. In varieties of Scottish and South African English, it is pronounced [r]. Northern Northumbria had a uvular /R/, which has become very rare if not almost extinct (Ogden 2009: 90-93), but has been in use "for at least the last 300 years" (Maguire 2017: 88).

In Middle English, be it in varieties which already had an approximant or in varieties which retained the trill or tap/flap, I found no traces of $s$-retraction in /rs/.

As Ball/Rahilly (1999: 56) point out concerning the retroflex approximant [x], “some speakers use a retroflex approximant as their realization of ' $r$ ', and if they pronounce final ' $r$ ' in words like 'reader' and then add a plural ending to this, the final sound may well be [z]". Retroflex assimilation is thus observed in rhotic varieties of English with a retroflex approximant, amongst which Scots and Scottish English. In those varieties, it is ascribed to Gaelic influence (Maguire 2012: 63), who mentions the occurrence of "retroflex approximant pronunciations of $/ \mathrm{r} /$, with retraction of following alveolars (as in horse [hols])". Retroflex assimilation can be found in a range of Northern English dialects as wide as from Yorkshire (Hedevind 1967: 73) and Cumbria (Cathcart 2012: 80f.) to Orkney (Schmitt 2015: 67f.) and the Hebrides (Cathcart 2012: 81), and occurs with all "following alveolar consonants" (Maguire 2012: 63).

In his short description of retroflex consonants in English, Orton (1939) notes that Northumbrian dialects have retroflex /t, $\mathrm{d}, \mathrm{s}, \mathrm{z}, \mathrm{n}, \mathrm{V}$ for the clusters / $\mathrm{rt}, \mathrm{rd}, \mathrm{rs}, \mathrm{rz}, \mathrm{rn}, \mathrm{rl} /$, and that the uvular /R/ is no longer pronounced in this context but seems to have "left its mark upon adjacent sounds" in the speech of "many people from all parts of the British Isles, especially Scotland" (Orton

10 Little is known about the precise period of the shift to an approximant, which has occurred at a different pace according to phonotactic context (e.g. [r] still being preserved in some clusters such as /thr/) and geographically (e.g. not having reached parts of Scotland). 
1939: 40). This allows the interpretation that Northumbrian dialects could have had productive $s$-retraction in /rs/ with a uvular /R/. However, considering the occurrence of retroflex and non-retroflex s-retraction in /rs/ (see next paragraph) in the neighbouring dialects with $[\imath]$ and $[r]$ respectively, the Northumbrian retroflexes might have been relics of an earlier retroflex assimilation with a coronal rhotic, or a consequence of language contact. Wells (1982: 370) cites Orton (1939) but gives as example of the backing of central vowels before a (now disappeared) Northumbrian uvular /R/ the word first [fo:st] (Wells 1982: 374f.), not [fJ:st], which even speaks against any s-retraction in /rs/ in Northumbrian dialects.

Some Scottish varieties of English with trilled [r] also have $s$-retraction in /rs/ as an active rule, inside words as well as across morpheme or word boundaries. For example, $s$-retraction after [r] can be heard distinctly in a dialect interview from the Isle of Skye, yielding e.g. of courshe or speakersh (BBC Voices, at 0:52 and 1:09). The speaker produces non-retracted non-sibilants after /r/ (e.g. words [w3:'ts] at 0:58), unlike other speakers with retroflex assimilation (e.g. start [sta:t] at 0:03), which underlines the difference between both phenomena despite their occurrence in the same region.

$S$-retraction with an approximant / $/$ / is also found in the clusters / str/, / skr/, /spr/ and /sr/ in English varieties of the United States, New Zealand and the United Kingdom (Baker/Archangeli/Mielke 2011; Stevens/Harrington 2016). Baker/ Archangeli/Mielke (2011: 359) note however that “/st $\mathrm{x} /$ strongly favors a bunched / $\mathrm{x}$ / over a retroflex $/ \mathrm{x} /$ and all of the subjects in [their] study produced a bunched $/ \mathrm{x} /$ variant [...] in /stu/ clusters". It thus seems that $s$-retraction in /str/ is triggered by

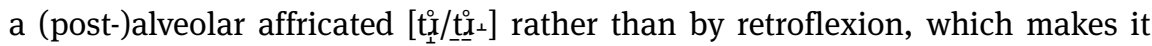
more similar to "non-retroflex" s-retraction. Rutter (2011: 31) mentions as a possible phonetic trigger the fact that "both $/ x /$ and $/ \int /$ share a tongue position that is further back than /s/", thus evoking an assimilation of place of articulation in /str/.

\subsection{Middle High German and modern German}

Starting from a pre-Old High German inventory with a sole /s/, the second Germanic consonant shift appeared around the sixth century in Upper German and spread gradually to Central German dialects (Stedje 2007: 75), transforming amongst others the $\mathrm{PG} \star / \mathrm{t} /$ into the affricate [t大s]. It was at first realised as an affricate in all positions (i.e. also after vowels, contrarily to modern German, see Lange 2007: 17), which means that Old High and Early Middle High German /s/ continued to be the sole member of its sibilant inventory, since the original PG */sk/ had not been assimilated to [ $]$ ] yet (similarly to the English palatalisation 
of /sk/). Old High and Early Middle High German thus had a sole /s/, which must have been a retracted alveolar $[\mathrm{s}] .^{11}$

The phonetic realisation of / $\mathrm{r}$ / was probably still identical to the PG trill * $[\mathrm{r}]$ in almost the entire German-speaking area up to the 18th century (see the map in Wiese 2011: 718), except for a small area in Southwest Austria which is claimed to have developed uvular /R/ autonomously in the Middle Ages (Bisiada 2009: 89-91).

Phonological s-retraction did not occur in Early Middle High German as long as /S/ [J] did not exist as a phoneme. Judging from MHG orthography, $s$-retraction did probably not occur phonetically or phonologically, since [s] after $/ \mathrm{r} /$ was written $\langle\mathrm{z}>$ and not $\langle\mathrm{s}\rangle$ (compare hirz in Engelien 1892: 46). In Middle High German, around the eleventh century (Hall 2008: 217), /sk/ became phonemicised as / $/$ / in all positions, creating a contrast with the original /s/ ([] $]$ ). Before the twelfth century as well, [ts] had become deaffricated to [s] after vowels, which made all three sibilants contrast with each other, [s] being rendered in the orthography as $\langle\mathrm{z}\rangle$, [s] as $\langle\mathrm{s}\rangle$, and [ $\int$ ] as <sch $>$ (Hall 2008: 218). The one-sibilant inventory of Early Middle High German thus became a three-sibilant inventory, with a contrast between [s], [s] and [J] (Adams 1975: 284; Benware 1996: 266f.). In the twelfth century, [s] merged with [s] to [s] (Hall 2008: 218), leading to a two-sibilant inventory consisting of /s/ [s] and $/ \int /\left[\int\right]$, as in modern German. The conditions necessary for phonological $s$-retraction to /rf/ were reunited, and s-retraction in /rs/ occurred (ibid.: 231f.).

This provides an answer to the actuation problem: $s$-retraction in /rs/ did not occur phonologically in Low German varieties, because they still had one single /s/ pronounced [s]. ${ }^{12}$ Dialects located north of the boundary of the $/ \mathrm{t} / \rightarrow /(\mathrm{t}) \mathrm{s} /$

11 Additional evidence supporting this view are Transylvanian place names, which demonstrate that the first German settlers who migrated from the Moselle and Rhine region to Transylvania in the 12th century still had a retracted [s] for /s/. Rosenau has been reanalysed in Romanian (which already had a contrast with [s] and [J]) as Râşnov ([rifinov]), and in Hungarian (which also has this contrast) both as (Barca)rozsnyo ([rozno]) and Rosznyó ([rosno:]) (Siebenbuerger.de: Rosenau). It must thus have been pronounced [s] or [z] in Early Middle Central German to have been interpreted as [ []$,[3]$ and [s] in Romanian and Hungarian, something which is cross-linguistically attested for the transfer of $[\mathrm{s}]$ and $[\mathrm{z}]$ into languages with a [s]-[J] contrast (Adams 1975). The same reanalysis is observed in other Transylvanian place names, e.g. Klausenburg (Rom. Cluj, Hun. Kolozsvár) (Siebenbuerger.de: Klausenburg). An [s] from PG */t/ consistently corresponds to Romanian [s], e.g. Weißkirch - Viscri (Siebenbuerger.de: Deutsch-Weisskirch). The merger of $\langle\mathrm{s}\rangle[\mathrm{s}]$ and $\langle\mathrm{z}\rangle[\mathrm{s}]$ as well as s-retraction in /rs/ occurred later as witnessed by place names, e.g. Donnerschmuert (Ger. Donnersmarkt), Hamerschderf (Hammersdorf) and Mäterschdref (Mettersdorf) (Siebenbuerger.de).

12 They had not assimilated /sk/-clusters to / // (compare e.g. [sk] in modern Afrikaans, meaning that dialects from South Holland in the 17th century still had unassimilated /sk/) and they had no [ts] to deaffricate at all (for not having taken part in the High German consonant shift). 
shift and south of the boundary of the /sk/ $\rightarrow / \delta /$ shift (i.e. dialects which have dat and Schule, e.g. in East Limburg) developed a contrast between the original $/ \mathrm{s} / \rightarrow[\mathrm{s}]$ and the assimilated $/ \mathrm{sk} / \rightarrow[\mathrm{J}]$. In these dialects, $s$-retraction in $/ \mathrm{rs} /$ could also happen, and did happen (see next paragraph).

Evidence demonstrating that only $[\mathrm{r}]$ and not uvular /R/ triggers s-retraction is given by different outputs in different diachronic lexical layers in the dialect of Eys (Dutch Limburg). The modern dialect uses uvular / $/$ / in all positions, and exactly as in standard German, s-retraction in /rs/ is no longer productive. Yet, in words which are old and common enough to belong to the vocabulary of Limburgish farmers of the 17th century, a historical and standard Dutch or German /rs/ corresponds to /(ə) $\int /$ (where $/ \mathrm{r} /$ vocalised to $/ \partial /$ in stressed syllables and disappeared in unstressed ones). Newer or "higher educated" words exhibit no trace of $s$-retraction, but contain [Rs] instead.
a. Eys dialect veë[ []$^{13}$
Ge. Ferse
En. heel
b. Ey. po[J]elei
Nl. porselein
En. porcelain
c. Ey. ange[3]öm
Nl. andersom
En. the other way around
d. Ey. get ange[]]
Nl. iets anders
En. something else
e. Ey. get bete[Rs]
Nl. iets beters
En. something better
f. Ey. Noo[Rs]
N1. Noors
En. Norwegian
g. Ey. peё[[]
Nl. pers
En. (fruit) press
h. Ey. $p e[\mathrm{RS}]$
Nl.pers
En. (written) press

The arrival of uvular / $\mathrm{R} /$ in the language can be dated to after the borrowing of posjelei "porcelain" from French or Dutch, but before the borrowing of pers "written press" from standard Dutch. Uvular /R/ impeded s-retraction in /rs/ to continue working in the Eys dialect, as can be observed in newer words and morphosyntactic constructions. In e.g. the Swiss dialect of Jaun, however (Stucki 1917; Hall 2008: 232), /r/ is realised as [r] and therefore, $s$-retraction is still active across morpheme and word boundaries.

\subsection{Middle Low German and modern Dutch and Frisian}

As detailed in the previous section, Middle Low German had a sole /s/ in its sibilant inventory, which was a retracted one (Adams 1975: 289). This retracted

13 Data provided by a native speaker of the Eys dialect. 
[s] has also historically been the variant used in the Low Countries until recent times, and it still is in Frisian and some Netherlandic varieties (compare the assumption made in Boersma/Hamann (2008: 230) that Dutch /s/ is [s] ). These varieties with retracted $[\underline{s}]$ are found mostly in e.g. Zeeland, Holland and Friesland (i.e. in the inner Low Countries, far from the border with French and Central German), whilst (dento-)alveolar [s] is found closer to the border with French and Central German, mainly in Flanders and Limburg. ${ }^{14}$ In all varieties, the phoneme $/ \mathrm{J} /$ is present in loanwords (e.g. China). Some West Flemish and Limburgish dialects have [ $\left.\int\right]$ in /sk/-clusters (Goossens/Taeldeman/Verleyen (eds.) 2000: 19), but the other varieties have unassimilated /sk/-clusters ([sk] or [sx]). Some varieties such as West Flemish, Netherlandic Dutch and Frisian assimilate clusters of /sj/ to [6] (e.g. meisje "girl"). This doesn't prevent the Netherlandic Dutch and Frisian varieties to keep /s/ pronounced as [s] , coexisting with [6] in a poorly dispersed sibilant inventory (Boersma/Hamann 2008: 230, 254). To sum up, Netherlandic Dutch and Frisian have sibilant inventories consisting of one retracted alveolar sibilant coexisting with [6] in /sj/ and [ $\left.\int\right]$ in loanwords; some West Flemish and Limburgish varieties have both [s] and [ $]$ ]; and other Flemish varieties have [s] and [ $]$ ] in loanwords only.

The phoneme $/ \mathrm{r} /$ in the Low Countries exhibits an even higher diversity of realisations, since "almost all variants of $/ r$ / found in the languages of the world [...] are observed in the Dutch language area" (Verstraeten/Van de Velde 2001: 45). The original alveolar trill or tap/flap $[\mathrm{r}]$ is rivalled by the more recent approximant [x] and uvular /R/. A glance into the phonological atlas of Dutch dialects (Goossens/Taeldeman/Verleyen (eds.) 2000: 357) shows that uvular /R/ is well-established along the Rhine and Meuse region, in Limburg and Brabant, as well as in cities (e.g. Ghent), spreading from one centre to another (Verstraeten/Van de Velde 2001: 46). The approximant is gaining ground in the Netherlands, and has become known as the Gooise $R$.

As explained in 2.2, in the varieties with a retracted [s], $s$-retraction in the phonological sense cannot occur because all occurrences of [s] are interpreted as /s/ regardless. Nevertheless, in Dutch varieties with [r] and [s], but not in those with uvular /R/ and [s], phonetic s-retraction in /rs/ occurs produc-

14 An acoustic analysis of /s/ in sound files of the Nederlandse Dialectenbank (van Oostendorp 2014) indeed shows that /s/ is more retracted in Dutch regions centred around Holland and the north (tested in Ouddorp, Zwanenburg and Hallum, with a mean centre of gravity of 3,784 $\mathrm{Hz}$ ), and in the speech of older people in the Low Countries. A fronted [s] is found in regions closer to French and German (tested in Tongeren, Elingen and Clairmarais, mean COG: 4,628 Hz), and in the speech of younger people. 
tively, as described in the next section. Due to a lack of data, nothing can be said here about Netherlandic Dutch varieties with an approximant $/ \mathrm{r} /$ and [s]. Nevertheless, Plug/Ogden (2003) show that in those varieties, /t/ and /d/ are pronounced as apical alveolars after an approximant $/ \mathrm{r} /$, whilst they are generally laminal in other contexts (Scobbie/Sebregts 2010). This suggests that the approximant could exert a similar influence on a following /s/, making it apical and thus prone to reanalysis as a posterior phoneme category (see section 3.1).

\subsubsection{A phonetic study of Flemish $s$-retraction in /rs/}

To quantify the observed Flemish s-retraction in /rs/, Kokkelmans (2017) proposes a pilot study which compares $/ \mathrm{s} /$ after $/ \mathrm{r} /$ to $/ \mathrm{s} /$ in other contexts and to $/ \mathrm{J} /$ in loanwords (including their voiced counterparts), in regional varieties of standard Dutch spoken by Flemish students. Six informants, with a homogeneous background in order to make results comparable and unperturbed by the potential influence of additional factors (native Flemish men between 18 and 30 years old, with a higher education background), were recorded reading the same text, and subsequently holding a colloquial conversation with the interviewer. Three of them are from East Flanders, one is from West Flanders, one from Brabant and one from the province of Antwerp. Four of them use an alveolar trill $/ \mathrm{r} /$ in usual speech, two use a uvular /R/, and all pronounce /s/ as a (dento-)alveolar [s]. They are anonymously labelled Alveolar1, Alveolar2, Uvular1, Uvular2 etc. according to their own place of articulation for $/ \mathrm{r} /$, i.e. either $[\mathrm{r}]$ or $/ \mathrm{R} /$. All speak regional varieties of standard Dutch, with a moderate extent of regional or local features. No participant knew what the experiment was about, with the purpose of guaranteeing a spontaneous speaker input.

Calculations were made using Praat (Boersma/Weenink 2005) on the acoustic characteristics of sibilants contained in a total number of 64 different words:

- 37 words containing the cluster/rs/

-13 containing its voiced equivalent / rz/

- 3 containing /s/ in another context (e.g. steden "cities")

- 3 containing / $/$ / in another context (e.g. zouden "should")

-3 containing /J/ (e.g. pêche "peach", loanword from French)

-3 containing /3/ (e.g. journal in English, with the exclusion of the preceding $/ \mathrm{d} /$ )

- 2 Dutch words containing /sj/ (nationale and sociale), to test if speakers realise it as $[6]$ or $[\mathrm{sj}]$ 
These 64 words were all to be read in the same (con)text by the 6 informants, so that no different phonetic context could interfere. All 374 sibilant realisations ${ }^{15}$ were manually extracted in Praat, and an automated Praat script calculated the COG of the extract to determine "how sh-like" the sibilant is. As Ladefoged (2001: 56) explains, [s] is characterised by "a large amount of energy in the upper part”, “comparatively little energy below 3,500 $\mathrm{Hz}$, and a noticeable intense band above 5,000 Hz". In turn, [ $]$ ] "has more energy at a slightly lower frequency, centered at a little above 3,000 Hz". Similarly, the difference between voiced [z] and [3] consists of a lower concentration of energy for the latter.
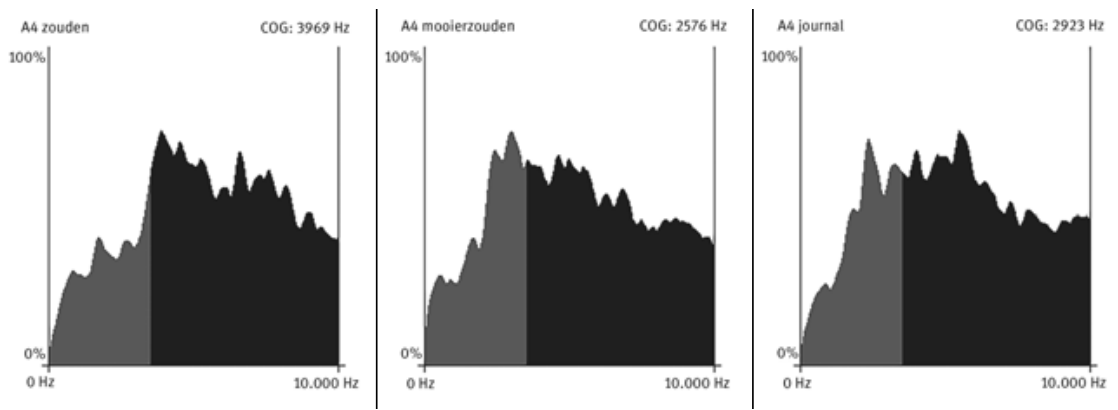

Fig. 1: Graphs representing the mean intensity (vertical axis) in function of the frequency (horizontal axis), for / $z$ / in "zouden" and "mooier zouden", and / 3 / in "journal" (from left to right), produced by informant Alveolar4. The grey part corresponds to all frequencies below or equal to $3,500 \mathrm{~Hz}$.

As an example, the three graphs in figure 1 reveal the striking difference between $/ z$ / in zouden "should" when following an alveolar /r/ in the previous word, and $/ z /$ in zouden when not preceded by $[\mathrm{r}]$. Despite the word boundaries, $s$-retraction operates in this example to such an extent that /z/ after [r] is "even more [3]" than the $/ 3 /$ in journal pronounced by the same speaker.

The results for all 64 words of the study are illustrated in figure 2. As figure 2 shows, informants with alveolar /r/ have lower COG values (i.e. more "sh-like" pronunciations) for $/ \mathrm{s} /$ and $/ \mathrm{z} /$ when preceded by $/ \mathrm{r} /$ than in other contexts, but they are generally not as low as those of $/ \mathrm{J} /$ and $/ 3 /$. On a scale from the mean $/ \mathrm{J} /$ and $/ 3 /$

15 Out of the 384 predicted occurrences (64 words x 6 informants), 10 occurrences were excluded because the informant mispronounced the word or used another pronunciation, e.g. reading the sign "\%" as procent instead of percent. 
(3,185 and 3,055 Hz, respectively) to the mean /s/ and /z/ (4,933 and 3,742 Hz), the mean /s/ and /z/ after /r/ are located at 4,287 and 3,057 Hz respectively, i.e. 45.34\% "s-ness" if the mean $/ \mathrm{J} /$ and $/ 3 /$ correspond to $0 \%$ and the mean $/ \mathrm{s} /$ and $/ \mathrm{z} /$ to $100 \%$.

The two informants with uvular /R/ do not exhibit active $s$-retraction in /rs/. On a scale from the mean $/ \mathrm{J} /$ and /3/ (2,988 and 2,473 Hz) to the mean /s/ and /z/ (4,113 and 3,465 Hz), the mean /s/ and /z/ after /R/ are located at 4,781 and 2,991 Hz, i.e. $109.16 \%$ if the mean $/ \mathrm{J} /$ and $/ 3 /$ correspond to $0 \%$ and the mean $/ \mathrm{s} /$ and $/ \mathrm{z} /$ to $100 \%$.

An inquiry into individual mean values shows that $s$-retraction is the strongest in the speech of Alveolar1 (-22.55\%), followed by Alveolar3 (46.85\%), Alveolar4 (62.52\%) and Alveolar2 (65.64\%). Uvular1 (86.68\%) and Uvular2 (121.63\%) do not seem to have $s$-retraction as an active rule.

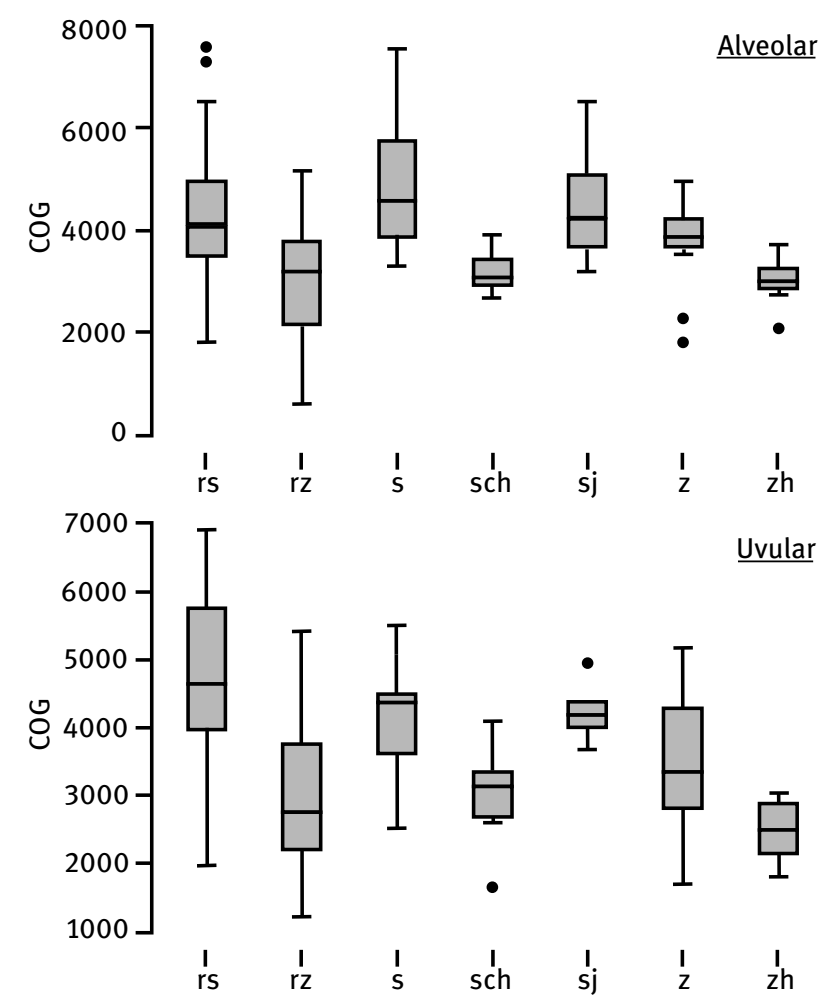

Fig. 2: Boxplot representation of the mean COG values for speakers with alveolar or uvular $/ r /$ in Kokkelmans (2017) according to phoneme and phonetic context, generated using the statistical software JASP (JASP Team 2018). <sch> stands for / $/$ and $\langle$ zh $>$ for $/ 3 /$. Dots represent outliers (i.e. exceptionally diverging values). 
A striking observation is that the informants who have the lowest mean COG values for /sj/ (indicating s-retraction to /6/, compare 3.3) are alveolar speakers with active $s$-retraction in /rs/, namely Alveolar1 (07.36\% for /sj/) and Alveolar3 (56.04\% for /sj/). On the contrary, Uvular2 (80.75\%), Alveolar4 (98.60\%), Alveolar2 (99.68\%) and Uvular1 (148.72\%) do not productively retract /sj/ towards [6]. This could mean that $s$-retraction in /rs/ favours $s$-retraction in /sj/ (and perhaps also the other way around). This pattern resembles the one observed in the MHG $s$-retraction after $/ \mathrm{r} /$ and before consonants, with $s$-retraction in a specific context (e.g. before /p/) triggering $s$-retraction in other contexts (e.g. before /n/), i.e. "dragging” other clusters towards / $/$ / (described as "processual change" in Benware 1996: 268, 275). One can thus conclude that these Flemish varieties with alveolar [r] exhibit the same phenomenon of productive $s$-retraction in /rs/-clusters as Middle High German.

\section{Final observations and conclusion: Answering the actuation problem}

The cross-linguistic part of this study has focused in detail on West Germanic languages. However, other languages also show traces of once-productive $s$-retraction in $/ \mathrm{rs} /$, or have it as a productive rule.

In the Germanic family, a large group of Faroese, Swedish and Norwegian varieties have active retroflex assimilation in /rs/-clusters to [s], also across morpheme and word boundaries (Eliasson 2000: 40f.). As explained in sections 2.2 and 4.1, this kind of $s$-retraction is different from the one described here, in the sense that it applies to all alveolar consonants preceded by /r/ (also /t, d, n, 1/). Exactly as for "non-retroflex" s-retraction, retroflex assimilation and uvular /R/ are mutually exclusive in Scandinavia (Torp 2001), despite their co-occurrence in Frogner and Arendal, as detailed in section 2.2. Torp (2001: 82) remarks concerning this exception to the complementary distribution of /R/ and retroflexion that we "have to reckon with some special kind of dialect contact in order for the dorsal $/ \mathrm{r} /$ to penetrate into a dialect area with retroflexes".

10,000 kilometres further south, $s$-retraction in /rs/ also occurs productively in Afrikaans, according to recent phonetic analyses (Ewald 2015; Wissing/Pienaar/Van Niekerk 2015) which found /s/ to be realised after the alveolar [r] "as a voiceless retracted alveolar sibilant [s] " (Ewald 2015: 35) instead of [s]. This must be an independent rather than inherited phonological development, since Afrikaans is mainly based on dialects from southern Holland (Kloeke 1950), which still today have a retracted alveolar [s] . 
$S$-retraction in /rs/ also happened in Indo-European satem languages such as Balto-Slavic and Indo-Iranian, in contexts in which /s/ was preceded by /r/, /u/, /k/ or /i/ (known as the ruki-rule, see Pedersen 1895: 53f., 74). In this case, $s$-retraction in $/ \mathrm{rs} /$ only started to operate phonologically after the $/ \mathrm{s} /-/ \mathrm{J} / \mathrm{con}$ trast appeared (from the assibilation of the PIE palatovelar series */k, g, $\mathrm{g}^{\mathrm{h}} /$ ), triggered by an $/ \mathrm{r} /$ pronounced (most probably) as an alveolar trill or tap/flap (which is still the pronunciation of $/ \mathrm{r} /$ in almost all their daughter languages).

Outside the Indo-European language family, Western Basque varieties are found to have a single $<\mathrm{s}>$ (apical [s]) corresponding to historical [rs]-clusters, whereas Eastern varieties have retained $<\mathrm{rz}>$ ([rs]), as e.g. in uso [u.so] vs. urzo [ur. so], “pigeon, dove” (Trask 1996: 77). This example of $s$-retraction in /rs/ with r-drop perfectly corroborates the hypothesis of a retracted alveolar place of articulation and apical tongue shape assimilation, since the phonetic output $[\mathbf{s}]$ is preserved exactly as such in the phoneme /s/ which exists in the language, and not reanalysed as the laminal $/ \mathrm{J} /\langle\mathrm{x}\rangle$ which also exists in Basque's three-sibilant inventory. In Western and Central Basque, /r/ surfaces as an alveolar trill or tap/flap, unlike in the French (i.e. Eastern) Basque country, where it has partly become a uvular /R/ (McColl Millar/Trask 2015: 285).

The typologically recurring pattern observed here confirms the hypothesis of this paper: $s$-retraction in /rs/-clusters only arises phonetically in languages with an alveolar /r/ and a (dento-)alveolar /s/, and phonologically in inventories with an /s/ [s] and at least one other more posterior category. This provides an answer to the actuation problem: by knowing which phonetic properties and which phonological inventories allow $s$-retraction in /rs/ to start operating, one can explain why it does or does not occur productively in different languages.

In the context of the general shift, in IE languages, from a one-sibilant inventory with [s] (Adams 1975: 290) to one with several contrasting sibilants, Low German, Dutch and Frisian have shown themselves to be the most conservative West Germanic varieties by keeping their sole retracted [s] up to recent times. English first lead the innovation of phonemicising $/ \mathrm{J} /$, and later experienced $s$-retraction in $/ \mathrm{rs} /$ in its varieties with $[\mathrm{r}]$ and $[\mathrm{r}]$. At the other end of the West Germanic family, High German phonemicised / / from the same /sk/-cluster and also underwent $s$-retraction, which did not reach as far north as northern Germany and the Low Countries because of their conservative sibilant inventory. It has thus been shown that as soon as the required conditions are met, all Germanic languages start to undergo s-retraction in /rs/, something which sheds light on how related languages experience parallel developments in the same direction despite being separated from each other (compare e.g. Flemish and Afrikaans). On the other hand, I found no trace of $s$-retraction in /rs/ at all in Romance languages. This leads to the crucial observation that although both groups arose from a variety 
which could not and did not experience $s$-retraction in /rs/, namely Proto-Germanic and Latin, only the members of the former language group later developed in that direction regardless of geographical barriers. This raises the question to which extent the potentiality of $s$-retraction in /rs/ was already "contained in the grammar" of Proto-Germanic and not in that of Latin. This question opens possibilities for further investigation in the domain of the underlying phonological grammars, to address the questions which remain with respect to the actuation problem.

\section{References}

Adams, Douglas Q. (1975): The distribution of retracted sibilants in medieval Europe. In: Language 51, 2. 282-292.

Anderson, Victoria B. (1997): The perception of coronals in Western Arrernte. In: Kokkinakis, George/Fakotakis, Nikos/Dermatas, Evangelos (ed.): Proceedings of the 5th European Conference on Speech Communication and Technology (Eurospeech 1997), Rhodes, Greece. Vol. 1. Grenoble: ESCA. 389-392.

Baker, Adam/Archangeli, Diana/Mielke, Jeff (2011): Variability in American English s-retraction suggests a solution to the actuation problem. In: Language Variation and Change 23, 3. 347-374.

Ball, Martin John/Rahilly, Joan (1999): Phonetics: The science of speech. London/New York: Routledge.

Barry, William John (1997): Another R-tickle. In: Journal of the International Phonetic Association 27, 1/2. 35-45.

Benware, Wilbur A. (1996): Processual change and phonetic analogy. Early New High German $\langle\mathrm{s}\rangle\rangle\langle\mathrm{sch}\rangle$. In: American Journal of Germanic Linguistics and Literatures 8, 2. 265-287.

Bisiada, Mario (2009): [R] in Germanic dialects - tradition or innovation? In: Vernaculum 1. 84-99.

Boersma, Paul/Hamann, Silke (2008): The evolution of auditory dispersion in bidirectional constraint grammars. In: Phonology 25, 2. 217-270.

Boyce, Suzanne (2015): The articulatory phonetics of / $r$ / for residual speech errors. In: Seminars in Speech and Language 36, 4. 257-270.

Catford, John C. (1977): Fundamental problems in phonetics. Bloomington: Indiana University Press.

Cathcart, Chundra (2012): Articulatory variation of the alveolar tap and implications for sound change. In: UC Berkeley Phonology Lab Annual Report. 76-110.

Cercignani, Fausto (1983): The development of */k/ and */sk/ in Old English. To the memory of Giorgio Dolfini. In: The Journal of English and Germanic Philology 82, 3. 313-323.

Chambers, Jack K./Trudgill, Peter (1998): Dialectology. Cambridge: Cambridge University Press.

Chen, Matthew Y./Wang, William S.-Y. (1975): Sound change. Actuation and implementation. In: Language 51, 2. 255-281.

Dart, Sarah N. (1991): Articulatory and acoustic properties of apical and laminal articulations. (= UCLA Working Papers in Phonetics 79). Los Angeles: Phonetics Laboratory.

Eliasson, Stig (2000): Typologiska och areallingvistiska aspekter på de nordeuropeiska språkens fonologi. In: Jahr, Ernst Håkon (ed.): Språkkontakt. Innverknaden frå nedertysk på andre nordeuropeiske språk. Copenhagen: Nordisk ministerråd. 21-70.

Engelien, August (1892): Grammatik der neuhochdeutschen Sprache. Berlin: Schultze. 
Ewald, Otto (2015): A spectral analysis of the backing of Afrikaans / $\mathrm{s} /$ in the consonant cluster /rs/. In: Malin, Svensson Lundmark/Ambrazaitis, Gilbert/Van de Weijer, Joost (eds.): Working Papers 55. Proceedings from Fonetik 2015. Lund: Lund University. 35-39.

Goossens, Jan/Taeldeman, Johan/Verleyen, Geert (eds.) (2000): FAND (Fonologische Atlas van de Nederlandse Dialecten). Ghent: Koninklijke Academie voor Nederlandse Taal- en Letterkunde.

Hall, Tracy A. (2008): Middle High German [rs] > [r] ] as height dissimilation. In: Journal of Comparative Germanic Linguistics 11, 3. 213-248.

Hedevind, Bertil (1967): The dialect of dentdale in the West Riding of Yorkshire. Uppsala: Appelberg.

Kloeke, Gesinus G. (1950): Herkomst en groei van het Afrikaans. Leiden: Leiden University Press. Kokkelmans, Joachim (2017): Die Achillesfersche einer Lautverschiebung im Vollzug. Postalveolarisierung, Retroflektierung und r-Schwund bei / rs/ in flämischen Umgangssprachen und den germanischen Sprachen, sowie deren Beziehung zu den Aussprachearten von $/ r /$. Master's thesis. Ghent: Universiteit Gent. https://lib.ugent.be/en/catalog/rug01:002349160 (last accessed: 14-8-2019).

Kwakkel, Vincent (2008): Sibilants in Dutch and English. Typologies, learning tasks and language change. Master's thesis. Utrecht: Universiteit Utrecht.

Ladefoged, Peter (2001): Vowels and consonants. An introduction to the sounds of languages. Oxford: Blackwell.

Ladefoged, Peter/Maddieson, Ian (1996): The sounds of the world's languages. Oxford: Blackwell. Lange, Klaus-Peter (2007): Der galloromanische Ursprung der zweiten Lautverschiebung. In: RASK (Internationalt tidsskrift for sprog og kommunikation Odense) 25. 3-24.

Lass, Roger (1997): Historical linguistics and language change. (= Cambridge Studies in Linguistics 81). Cambridge: Cambridge University Press.

Maguire, Warren (2012): English and Scots in Scotland. In: Hickey, Raymond (ed.): Areal features of the anglophone world. (= Topics in English Linguistics 80). Berlin: De Gruyter. 53-78.

Maguire, Warren (2017): Variation and change in the realisation of $/ r /$ in an isolated Northumbrian dialect. In: Montgomery, Chris/Moore, Emma (eds.): Language and a sense of place: Studies in language and region. Cambridge: Cambridge University Press. 87-104.

Martinet, André (1955): Économie des changements phonétiques. (= Bibliotheca Romanica 1). Bern: Francke.

McColl Millar, Robert/Trask, Larry (2015): Trask's historical linguistics. 3rd fully revised and updated edition. Oxford: Routledge.

Ogden, Richard (2009): An introduction to English phonetics. Edinburgh: Edinburgh University Press.

Orton, Harald (1939): ^عtıoofleks kbnsənənts ın ınglı.. In: Le Maître Phonétique 67. 40-41.

Pedersen, Holger (1895): Das indogermanische s im Slavischen. In: Indogermanische Forschungen 5, 1. 33-86.

Plug, Leendert/Ogden, Richard (2003): A parametric approach to the phonetics of postvocalic /r/ in Dutch. In: Phonetica 60, 3. 159-186.

Russ, Charles Victor Jolyon (1978): Historical German phonology and morphology. (= Oxford History of the German Language 2). Oxford: Oxford University Press.

Russ, Charles V. J. (1982): Studies in historical German phonology. A phonological comparison of MHG and NHG with reference to modern dialects. Bern: Lang. 
Rutter, Ben (2011): Acoustic analysis of a sound change in progress: The consonant cluster /stı/ in English. In: Journal of the International Phonetic Association 41, 1. 27-40.

Schmitt, Holger (2015): Orkney English phonology: Observations from interview data. In: Scottish Language 34. 58-81.

Scobbie, James M./Sebregts, Koen (2010): Acoustic, articulatory and phonological perspectives on rhoticity and /r/ in Dutch. In: Folli, Rafaella/Ulbrich, Christiane (eds.): Interfaces in linguistics: New research perspectives. (= Oxford Studies in Theoretical Linguistics 31). Oxford: Oxford University Press. 257-277.

Shariatmadari, David (2006): Sounds difficult? Why phonological theory needs 'ease of articulation'. In: SOAS Working Papers in Linguistics 14. 207-226.

Stausland Johnsen, Sverre (2012): A diachronic account of phonological unnaturalness. In: Phonology 29, 3. 505-531.

Stedje, Astrid (2007): Deutsche Sprache gestern und heute: Einführung in Sprachgeschichte und Sprachkunde. 6th edition. Munich/Paderborn: Fink.

Stevens, Mary/Harrington, Jonathan (2016): The phonetic origins of /s/-retraction: Acoustic and perceptual evidence from Australian English. In: Journal of Phonetics 58. 118-134.

Stucki, Karl (1917): Die Mundart von Jaun im Kanton Freiburg: Lautlehre und Flexion. (= Beiträge zur Schweizerdeutschen Grammatik 10). Frauenfeld: Huber.

Torp, Arne (2001): Retroflex consonants and dorsal / r/: Mutually excluding innovations? On the diffusion of dorsal / $r$ / in Scandinavian. In: Van de Velde, Hans/van Hout, Roeland (eds.): 'r-atics: Sociolinguistic, phonetic and phonological characteristics of $/ r /$. (= Études \& Travaux 4). Brussels: ULB. 75-90.

Trask, Robert Larry (1996): “Coalescence”. In: Trask, Robert Larry (ed.): A dictionary of phonetics and phonology. London: Routledge.

Trautmann, Moritz (1880): Besprechung einiger schulbücher nebst bemerkungen über die r-Laute. In: Anglia - Journal of English Philology 3. 204-222.

van Oostendorp, Marc (2014): Phonological and phonetic databases at the Meertens Institute. In: Durand, Jacques/Gut, Ulrike/Kristoffersen, Gjert (eds.): The Oxford Handbook of Corpus Phonology. Oxford: Oxford University Press. 546-551.

Verstraeten, Bart/Van de Velde, Hans (2001): Socio-geographical variation of / $r /$ in standard Dutch. In: Van de Velde, Hans/van Hout, Roeland (eds.): r-atics: Sociolinguistic, phonetic and phonological characteristics of $/ r /$. (= Études \& Travaux 4). Brussels: ULB. 45-62.

Vijūnas, Aurelijus (2010): The Proto-Indo-European sibilant */s/. In: Historical Linguistics 123. 40-55.

Weinreich, Uriel/Labov, William/Herzog, Marvin I. (1968): Empirical foundations for a theory of language change. In: Lehmann, Winfred P./Malkiel, Yakov (eds.): Directions for historical linguistics. A symposium. Austin: University of Texas Press. 95-195.

Wells, John C. (1982): Accents of English. Vol. 2: The British Isles. Cambridge: Cambridge University Press.

Wiese, Richard (2011): The representation of rhotics. In: van Oostendorp, Marc/Ewen, Colin J./ Hume, Elizabeth/Rice, Keren (eds.): The Blackwell companion to phonology. Vol. 1: General issues and segmental phonology. Oxford: Blackwell. 711-729.

Wissing, Daan/Pienaar, Wikus/Van Niekerk, Daniel (2015): Palatalization of /s/ in Afrikaans. In: Stellenbosch Papers in Linguistics Plus 48. 137-158. 


\section{Online references}

BBC Voices: http://sounds.bl.uk/Accents-and-dialects/BBC-Voices/021M-C1190X0043XX-3001V0 (last accessed: 15-12-2016).

Boersma, Paul/Weenink, David (2005): Praat: doing phonetics by computer [computer program]. www.praat.org (last accessed: 7-8-2019).

Datenbank für gesprochenes Deutsch (DGD): http://dgd.ids-mannheim.de. (last accessed: 24-10-2017).

JASP Team (2018): JASP (version 0.8.5) [computer program]. https://jasp-stats.org/. (last accessed: 5-1-2018).

Siebenbuerger.de: www.siebenbuerger.de/ortschaften/ (last accessed: 29-12-2017).

UPSID: http://web.phonetik.uni-frankfurt.de/upsid_info.html (last accessed: 6-8-2018). 